\title{
SURGICAL CONSIDERATION ON THE COMBINED VALVULAR DISEASES WITH TRICUSPID INSUFFICIENCY
}

\author{
KIROKU OHISHI, SHOJI TOKUNAGA, MICHIYASU NONAKA \\ AND MICHIHIRO KOGA
}

Second Department of Surgery, Kurume University School of Medicine, Kurume, 830, Japan

(Received for publication December 23, 1975)

\begin{abstract}
Among acquired valve diseases, surgical results are not quite satisfactory in combined valve diseases with tricuspid insufficiency. We classified tricuspid insufficiency into three grades depending on the degree of regurgitation through the tricuspid valve and surgical results including hemodynamic changes after surgery and prognosis were studied from the point of relation to the degree of regurgitation.
\end{abstract}

Tricuspid insufficiency as an acquired valve disease is mainly due to secondary change in another valve which has primary lesion, therefore, symptoms in those patients are quite severe and improved very poorly even by surgical treatments. We tried to evaluate this fact from the surgical points of view.

Firstly, we classified the tricuspid insufficiency into 3 grades by the degree of regurgitation through the tricuspid valve shown in the right ventriculogram $^{\text {s) }}$ (Table 1).

In grade I, contrast dye in the right atrium was less concentrated than that in the main pulmonary artery. In grade II, the right atrium showed up earlier than the pulmonary artery. In grade III, the dye regurgitated into the great veins. In addition to the findings of the right ventriculogram we made sure of the regurgitation by palpating the jet flow through the tricuspid valve during operation. In grade I, jet flow
TABLE 1

Classification of tricuspid insufficiency $(T I)$

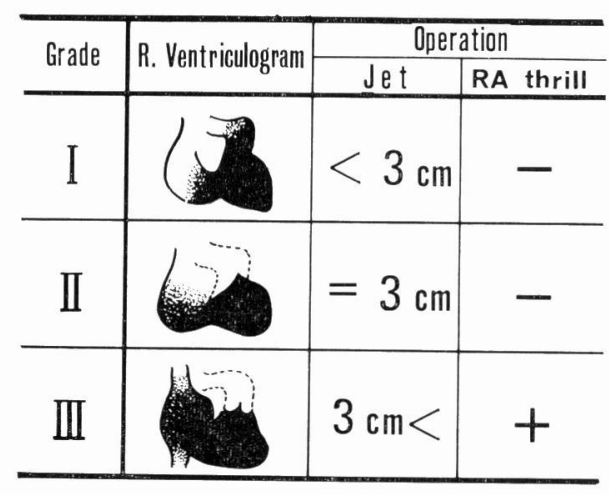

was palpated jut tabove the orifice of the valve. In grade II, jet flow was palpated even in the position of $3 \mathrm{~cm}$ away from the orifice. In grade III, jet flow was palpated practically all over the valve area and thrill was palpated on the right atrial wall. Grade II and 
III were scheduled for surgical treatment on the tricuspid valve as well as on the other valve which had the primary lesion.

We have 670 cases of the acquired valve diseases operated on in our institute and 96 cases, which were $14.3 \%$ of total, were found to have a tricuspid insufficiency combined with other valve lesions (Table 2).

TABLE 2

Incidence of $T I$ and operative results

\begin{tabular}{c|c|c|c|c|c|c}
\hline Disease & $\begin{array}{c}\text { No. of } \\
\text { case }\end{array}$ & $\begin{array}{c}\text { With } \\
\text { TI }\end{array}$ & \multicolumn{3}{|c|}{ Operation's method } \\
op. & AP & TVR & TVA \\
\hline M S & 416 & 38 & 20 & 16 & 1 & 1 \\
& & $(9)$ & $(3)$ & $(5)$ & $(1)$ & $(0)$ \\
M I & 98 & 8 & 4 & 3 & 1 & \\
M I & 65 & $\begin{array}{c}(4) \\
(8)\end{array}$ & 5 & $(2)$ & $(1)$ & \\
A & 22 & 0 & & $(2)$ & & \\
M+A & 69 & 32 & 19 & 12 & 1 & \\
& & $(14)$ & $(7)$ & $(6)$ & $(1)$ & \\
\hline Total & 670 & 96 & 48 & 44 & 3 & 1 \\
& & $(31)$ & $(13)$ & $(15)$ & $(3)$ & $(0)$ \\
\hline
\end{tabular}

AP : Annuloplasty

TVR: Tricuspid valve replacement

TVA : Tricuspid valve advancement

( ) Death

We performed surgical treatment on the tricuspid valve in 48 cases. We did annuloplasty ${ }^{3)}$ in 44 cases and we lost 15 , mortality was $34 \%$, valve replacement ${ }^{7}$ was performed in 3 cases and we lost them all. We did valve advancement in one case and he is doing well now. We lost 13 out of 48 cases in which we didn't do any surgical treatment on the tricuspid valve because they had only mild regurgitations. Mortality was $27 \%$.

Table 3 shows the relation between the grade of the regurgitation and the postoperative mortality rate. We had 44 cases of Grade I tricuspid insufficiency, in which no surgical treatment was performed on the tricuspid valve, we lost 11 . Mortality rate was $25 \%$. Out of 42 cases of Grade II tricuspid insufficiency. We lost 13. Mortality was $31 \%$. With Grade III insufficiency we lost 7 out of 10 . Mortality rate was $70 \%$. In general, the more severe regurgitation seems to increase the mortality rate. Compared with the postoperative mortality of single valve disease which is less than 10\%, combined tricuspid insufficiency shows a higher mortality rate of $32 \%$.

TABLE 3

TI grades and operative results

\begin{tabular}{|c|c|c|c|c|}
\hline \multirow{2}{*}{ Op. method } & \multirow{2}{*}{$\begin{array}{l}\text { No. of } \\
\text { case }\end{array}$} & \multicolumn{3}{|c|}{ TI grade } \\
\hline & & I & II & III \\
\hline $\mathrm{AP}$ & $\begin{array}{l}44 \\
(15)\end{array}$ & 0 & $\begin{array}{l}39 \\
(12)\end{array}$ & $\begin{array}{l}5 \\
\text { (3) }\end{array}$ \\
\hline TVR & $\begin{array}{l}3 \\
(3)\end{array}$ & 0 & 0 & $\begin{array}{l}3 \\
\text { (3) }\end{array}$ \\
\hline $\mathrm{TVA}$ & $\begin{array}{l}1 \\
(0)\end{array}$ & 0 & 0 & $\begin{array}{l}1 \\
(0)\end{array}$ \\
\hline Non op. & $\begin{array}{l}48 \\
(13)\end{array}$ & $\begin{array}{l}44 \\
(11)\end{array}$ & $\begin{array}{l}3 \\
(1)\end{array}$ & $\begin{array}{l}1 \\
\text { (1) }\end{array}$ \\
\hline Total & $\begin{array}{l}96 \\
(31)\end{array}$ & $\begin{array}{l}44 \\
(11)\end{array}$ & $\begin{array}{l}42 \\
(13)\end{array}$ & $\begin{array}{l}10 \\
(7)\end{array}$ \\
\hline
\end{tabular}

AP : Annuloplasty

TVR: Tricuspid valve replacement

TVA: Tricuspid valve advancement

( ) Death

Figure 1 shows the relation between mean right atrial pressure and systolic pulmonary pressure in various condition of tricuspid insufficiency. Marks enclosed by white show survival patients and white marks show dead patients. Circle represents the patient who has Grade I insufficiency, triangle represents Grade II insufficiency. Square represents Grade III. There was increasing 
mortality in the range of mean right atrial pressure over $10 \mathrm{mmHg}$ and systolic pulmonary arterial pressure over $50 \mathrm{mmHg}$. We lost two patients with mean right atrial pressure less than 10 $\mathrm{mmHg}$ shown by arrows from thrombosis after tricuspid valve replacements. From our experiences, we feel it quite difficult to manage patients after operation when they did'nt have any surgical treatment on the tricuspid valve or when they had residual insufficiency. So we feel strongly that the tricuspid insufficiency with over Grade II regurgitation should be repaired surgically.

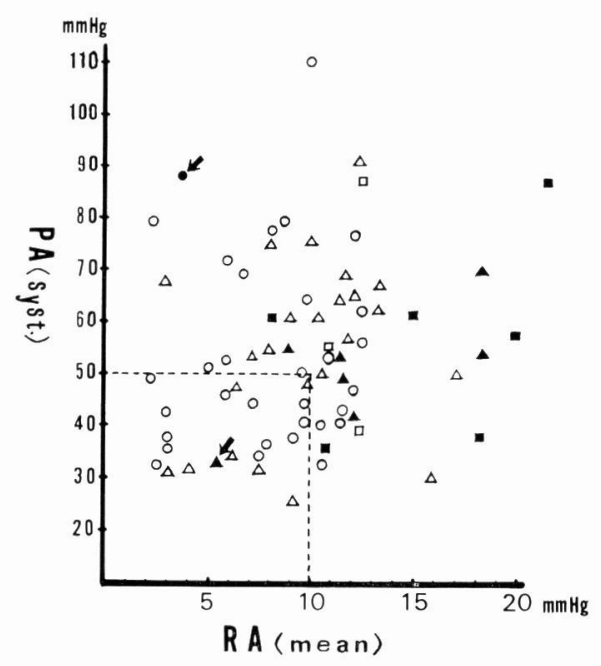

Fig. 1 Relation between PA systolic pressure and RA mean pressure in various condition of TI.

TI Grade I \begin{tabular}{ccc}
\multicolumn{3}{c}{ (Survival) (Death) } \\
Grade II & $\Delta$ & a \\
Grade III & $\square$ & .
\end{tabular}

We followed up postoperative patients for 7 years. Figure 2 shows the changes in their functional capacity after operation. In Grade I insufficiency, with no surgical treatment performed on the tricuspid valve, $73 \%$ of the patients
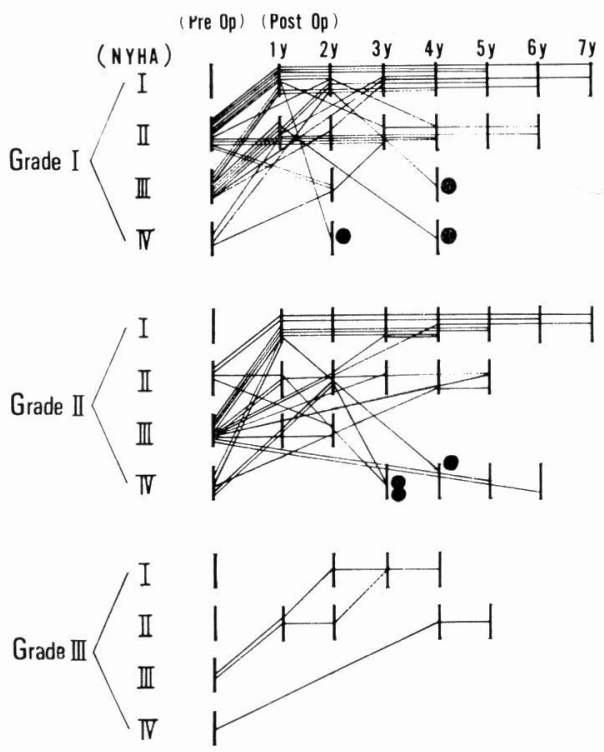

Fig. 2 Postoperative changes in functional capacity.

- Death

showed improvements, $25 \%$ showed no changes and $2 \%$ got worse in the first year. After the second year, 35\% showed improvements, 55\% showed no changes and 15\% got worse. We lost 3 of them from thrombosis as a complication of other valve replacements. In Grade II insufficiency, surgical treatment was performed in almost every patient. $84 \%$ showed improvement in the first year. 6 patients got worse, we lost 2 of them from thrombosis after other valve replacement. In another four patients we didn't perform surgical treatment on the tricuspid valve. In Grade II, we have only three cases. Annuloplasty was done in two of them and valve advancement was performed in one patient and all of them showed improvements and they are doing well even now.

Figure 3 shows how well the patients got used to their lives again after operation. Good represents a full life without any limitations. Fair represents an 
ordinary life with certain limitations, and poor represents readmission to hospital. In isolated mitral stenosis $79.5 \%$ were Good, $11.0 \%$ were Faer, $2.0 \%$ were Poor. Late death occured in $7.4 \%$. In tricuspid insufficiency combined with mitral stenosis $64.3 \%$ were Good, $14.7 \%$ were Fair, 5.3\% were Poor. Late death occured in $16.1 \%$. Apparently, tricuspid insufficiency makes the operative results worse.

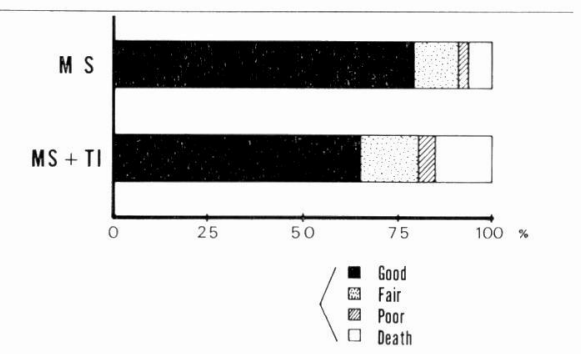

Fig. 3 How well the patients adapt to their lives again.

\section{DISCUSSION}

It is quite seldom that the tricuspid in sufficiency (TI) itself becomes target for surgical treatment but TI is often seen in mitral or aortic valve diseases as a secondary lesion. Therefore, it had been believed that surgical treatment on the primary lesion was good enough to reduce or abolish tricuspid insufficiency. Braunwald ${ }^{1)}$ noted that TI was improved or ablished after mitral valve replacement was done so surgical treatment on the tricuspod valve was rarely needed. But, recently, some of the cases which had valve replacement or valvoplasty on the advanced primary lesion already in open heart surgery happen to show low cardiac output syndrome or right heart failure in spite of improvement of primary lesion after surgery. Sinclair-Smith ${ }^{6)}$ measured the regurgitant fraction before and after surgery in the cases which they didn't do any surgical treatment on the tricuspid valve and concluded TI was not improved after surgery. We also experienced the case with above II nd degree of regurgitation through the tricuspid valve showed poor surgical resuit.

Therefore it is strongly felt that surgical treatment should be performed on the tricuspid valve with above II nd degree of regurgitation. Grondin ${ }^{2)}$ et al. found significant difference in surgical result between surgically treated TI group and untreated TI group in combined valve diseases. Surgical method for TI consists of annuloplasty ${ }^{3)}$, valve advancement and valve replacement ${ }^{7)}$ and but choice of method seems to be depend on who is going to operate. $\mathrm{Pluth}^{5)}$ et al. noted valve replacement showed the best surgical results in severe TI. We think annuloplasty should be a first choice of method (we are using modified Key's method.), but when the tricuspid valve showed severe organic changes on which annuloplasty would not be effective, we don't hesitate to perform valve replacement, we has been using disc valve ${ }^{4)}$ but since xenograft becomes widely used recently, we are also going to use it.

1. 96 patients out of 670 with the acquired valve diseases had combined tricuspid insufficiency, which was 14.3 $\%$.

2. We classified the tricuspid insufficiency into 3 grades by the degree of regurgitation shown in the right ventriculogram and palpted during operation.

3. Most of the tricuspid insufficiencies with mean a right atrial pressure over $10 \mathrm{mmHg}$ and systolic pulmonary arterial pressure over $50 \mathrm{mmHg}$ showed 
Grade II or Grade III regurgitation.

4. Annuloplasty and valve advancement are desirable methods for surgical treatment on the tricuspid valve and valve replacement should be done only on the hopeless valve.

5. Compared with the postoperative mortality of single valve disease, which was less than $10 \%$, combined tricuspid insufficiency shows a higher mortality of $32.2 \%$.

6. Surgical treatment should be considered on the tricuspid valve with II or III grade regurgitation.

\section{REFERENCES}

1) Braunwald, N.S., Ross, J.Jr. and Morrow, A.G.: Conservative management of tricuspid regurgitation in patients undergoing mitral valve replacement. Circulation, 35, Suppl. 1-63, 1967.

2 ) Crondin, P., Lepage, G., Gastonguay, Y. and MeEre, C.: The tricuspid valve: A surgical challenge. J. Thorac. Cardiov. Surg., 53, 7-14, 1967.

3) KAY, J. H. : Surgical treatment of tricuspid in sufficiency. Ann. Surg., 162, 53-60, 1965.

4) Kay, J. H., Kawashima, Y., Kagawa, Y, Tsuji, H.K. and Redington, J.V. : Experimental mitral valve replacement with a new disc valve. Ann. Thorac. Surg., 2, 485-492, 1966.

5 ) Pluth, J.R. and Ellis, F.H.Jr. : Tricuspid inssufficiency in patients undergoing mitral valve replacement. Conservative management, annuloplasty or replacement. J. Thorac. Cardiov. Surg., 58, 484-492, 1969.

6) Sinclair-Smith, B. C. : Diseases of the tricuspid valve in cardiovascular disorders, edited by Brest, A. N. and Moger, J. H., p. 626, 1968, F.A. Davis Company, Philadelphia.

7) StArr, A., Herr, R. and Wood, J. : Tricuspid replacement for aquired valve disease. Surg. Gynec. Obstet., 122, 1295-1302, 1966.

8 ) TAMAKI, E. : Diagnostic studies of tricuspid insufficiency. Jap. Circulat. J., 32, 1515-1521, 1968. 